\title{
Testing Hypotheses About Glacial Dynamics and the Stage 11 Paradox Using a Statistical Model of Paleo-Climate
}

5

\author{
Robert K. Kaufmann ${ }^{1}$, Felix Pretis ${ }^{2}$
}

${ }^{1}$ Department of Earth and Environment, Boston University, Boston, Massachusetts, USA, 02215

${ }^{2}$ Department of Economics, University of Victoria, Victoria, BC, Canada; and Nuffield College, University of Oxford, Oxford, UK

Correspondence to: Robert K. Kaufmann(Kaufmann@bu.edu)

\begin{abstract}
To test hypotheses about glacial dynamics, the Mid-Brunhes event, and the stage 11 paradox, we evaluate the ability of a statistical model to simulate climate during the previous $\sim 800,000$ years. Throughout this period, the model simulates the timing and magnitude of glacial cycles, including the saw-tooth pattern in which ice accumulates gradually and ablates rapidly, without nonlinearities or threshold effects. This suggests that nonlinearities and/or threshold effects do not play a critical role in glacial cycles. Furthermore, model accuracy throughout the previous $\sim 800,000$ years suggest that changes in glacial cycles associated with the Mid-Brunhes event, which occurs near the division between the out-of-sample period and the in-sample period, are not caused by changes in the dynamics of the climate system. Conversely, poor model performance during MIS stage 11 and Termination V is consistent with arguments that the 'stage 11 paradox' represents a mismatch between orbital geometry and climate. Statistical orderings of simulation errors indicate that periods of reduced accuracy start with significant reductions in the model's ability to simulate carbon dioxide, non-sea-salt sodium, and non-sea-salt calcium. Their importance suggests that the stage 11 paradox is generated by changes in atmospheric and/or oceanic circulation that affect ocean ventilation of carbon dioxide.
\end{abstract}

\section{Introduction}

25 When considered over the last eight-hundred thousand years, climate shows highly persistent movements. Most notable are glacial cycles. During glaciations, temperature, greenhouse gas concentrations, and sea level remain below their sample mean for extended periods; during these same periods, land and sea ice remain above their sample means. These positions are reversed for extended periods known as inter-glacials. These persistent movements and complex climate dynamics create difficulties for statistical analyses of climate data over this long time-span. Using ordinary least squares to analyze time series that show persistent movements tends to indicate statistically meaningful relations among time series when none are present (Yule, 1929; Engle and Granger, 1987). Monte Carlo simulations indicate a relation (based on $t$ statistics) for about 85 percent of random pairings of time series with highly persistent movements (Hendry and Juselius, 2000).

The difficulties posed by highly persistent movements and complex dynamics are greatly alleviated using the econometric methods of vector-autoregression, cointegration, and equilibrium correction. Using these methods, Kaufmann and Juselius (2013), herein KJ2013, estimate a statistical model of climate over the previous 391 thousand years. The model, termed a cointegration vector autoregression (CVAR), specifies four exogenous variables for orbital geometry; eccentricity, obliquity, precession, and summer time insolation at $65^{\circ}$ south to simulate ten endogenous 
variables that proxy various aspects of climate; Antarctic land and sea surface temperature, carbon dioxide and methane concentrations, land and sea ice, sea level, iron dust, and non sea-salt sulfate and calcium. The CVAR model explicitly represents long-run relations between climate and orbital geometry, which are given by ten cointegrating relations, and climate dynamics, which are given by the rates at which the climate system 'equilibrium corrects' from disequilibrium in the long-run (cointegrating) relations. Davidson et al., (2016) apply a similar approach for a subset of climate variables.

These relations validate some basic hypotheses about the mechanisms that are postulated to drive glacial cycles (e.g. carbon dioxide affects temperature via radiative forcing), reproduce the main features of glacial cycles (e.g. the timing, magnitude, and saw-tooth pattern of changes in land ice volume), and separate observed deglaciations from skipped obliquity/precession beats (e.g. Huybers, 2012), which are peaks in insolation, including obliquity that do not generate deglaciations (Huybers and Wunsch, 2005; Tzedakis et al., 2017). Subsequent analyses of the statistical model suggest a weak form of the Milankovitch hypothesis in which orbital geometry drives glacial cycles, with small perturbations imposed by internal climate dynamics (Kaufmann and Juselius, 2016).

Conclusions that are based on a model conditioned solely on orbital geometry are notable because many climate models cannot simulate atmospheric concentrations of $\mathrm{CO}_{2}$ (Archer et al., 2000). This has lead to hypotheses that orbital geometry and GHG are the 'two primary forcings' to the climate system (e.g. Yin and Berger, 2012). But KJ 2013 test and reject the hypothesis that carbon dioxide or methane is exogenous to the climate system; their concentrations are endogenous, driven by orbital geometry, which is exogenous to and is the primary driver of climate. Models that do simulate $\mathrm{CO}_{2}$ endogenously cannot simulate other aspects of climate jointly (e.g. ice volume) and so are simulated in absence of feedbacks (Brovkin et al., 2012) or in two steps (e.g. Ganopolski et al., 2016), which may cause models to understate the effects of changes in orbital position (Pretis and Kaufmann, in review).

Despite the strengths of the CVAR model, the resultant conclusions about the drivers of glacial cycles are tempered by the fact they are based on in-sample simulations over the previous 391 thousand years (i.e. the model simply reproduces the data from which it is estimated). A more rigorous methodology would use the four variables for orbital geometry to simulate the ten climate/physical variables for the entire period for which proxy data are available, which spans the previous $\sim 800$ thousand years.

Here, we simulate the model reported by KJ2013 for the previous 800 thousand years, which corresponds to the entire period recorded by the Dome C core. We evaluate model performance by computing the root mean square of the simulation errors (RMSE) and identifying periods when differences between simulated and observed values are statistically significant. These measures are used to test three hypotheses about glacial dynamics that have been discussed in the literature (see section 4 for discussion):

1. Nonlinearities, threshold effects, or phase-specific governing equations play an important role in the timing and magnitude of glacial cycles.

2. The Mid-Brunhes event (MBE), which refers to a climatic shift that occurs during the transition between marine isotope stage (MIS) 12 and MIS 11 (Jansen et al., 1986), changes the dynamics that drive glacial cycles.

3. The 'stage 11 paradox' represents a mismatch between orbital geometry and climate. 
Values for the RMSE and statistical differences between simulated values and values from the proxy record indicate that the model generally performs well during the in- and out-of-sample period. We interpret this general accuracy to indicate that:

1. Nonlinear relations,threshold effects, and/phase-specific governing equations do not play a critical role in glacial cycles.

2. Glacial cycles are driven by the same dynamics before and after the MBE.

3. Terminations in general - and the 'stage 11 paradox' in particular - may be caused by changes in atmospheric circulation and/or the extent of sea ice, which affects the ventilation of the deep ocean and ultimately, affects the atmospheric concentration of carbon dioxide.

10 These results and the methods used to obtain them are described in five sections. Section 2 describes the data and methods used to generate and analyze the simulations. The results are described in section 3 . Section 4 interprets the results relative to the three hypotheses described previously, and section 5 concludes.

\section{Methods}

15 The CVAR model described by KJ2013 is simulated in a dynamic simulation (equivalent to a dynamic forecast) conditioned on orbital geometry alone over the 791 thousand years before the present (kyr BP). Simulated values $\left(\hat{x}_{t}\right)$ are subtracted from the corresponding values from the proxy record $\left(x_{t}\right)$ to calculate simulation errors $\varepsilon_{t}=x_{t}-\hat{x}_{t}$. Simulation errors $\left(\varepsilon_{t}\right)$ are analyzed three ways. First, we compute the root mean square error (RMSE) to evaluate model accuracy over pre-defined periods. Second, simulation errors are analyzed to identify periods when the model

20 fails systematically, either in a single time step (outlier) or during two or more consecutive time steps (persisting errors). Third we examine the statistical ordering among simulation errors (and the explanatory power of simulations that are generated by conditioning the model on endogenous variables) to evaluate competing hypotheses for the 'stage 11 paradox,' which is a significant mismatch between orbital geometry and climate associated with marine isotope stage (MIS) 11, 424 - 375 kyr BP (Imbrie et al., 1993).

25

\subsection{Model Data}

The four series used to represent orbital position, the six series used to represent climate, and the four series used to represent physical and biological mechanisms that link the six climate variables to each other and orbital geometry are the same as those used in KJ2013 (Table 1). KJ2013 uses four series to represent the effect of orbital geometry: precession (Prec), obliquity $(\mathrm{Obl})$, eccentricity $(\mathrm{Ecc})$, and summer-time insolation at $65^{\circ} \mathrm{S}(\mathrm{SunSum})$. Observations for these time series are compiled back to $800 \mathrm{kyr}$ BP from the same sources used by KJ 2013 (Paillard, 1996).

KJ2013 uses these four measures of orbital geometry alone to simulate ten endogenous variables (six climate and four mechanisms); climate variables include land surface temperature (Temp), the atmospheric concentration of carbon dioxide $\left(\mathrm{CO}_{2}\right)$ methane $\left(\mathrm{CH}_{4}\right)$, sea surface temperature $(\mathrm{SST})$, land ice volume (Ice), and sea level (Level). Variables that capture mechanisms include iron dust $(\mathrm{Fe})$, sea-salt sodium $(\mathrm{Na})$, non sea-salt sulfate $\left(\mathrm{SO}_{4}\right)$, and non sea-salt calcium $(\mathrm{Ca})$; for additional details about the each series see Section I of the Supplemental Material. 
Data for Temp, $\mathrm{CO}_{2}$, and $\mathrm{CH}_{4}$ are obtained from cores drilled into the Antarctic ice sheet. Carbon dioxide and methane are well-mixed gases and so measurements from Antarctic ice proxy global concentrations. Temp represents local conditions, but can be converted to global values by assuming that a scaling factor, which is derived from a limited set of observations can be applied across all observations (Masson-Delmotte et al., 2010; Masson-Delmotte et al., 2006). The $\delta^{18} O$ data that are used to proxy ice volume, which also includes information about deep water temperature (Chappell and Shackleton., 1986; Shackleton, 2000), are derived from 57 cores drilled by the Deep-Sea Drilling Project and Ocean Drilling Program across the globe (Lisiecki and Raymo, 2005). Sea surface temperature is constructed using alkenones from site PS2489-2/ODP1090 in the sub-Antarctic Atlantic. Data for sea level are reconstructed using oxygen isotope records from Red Sea sediments (Siddall et al., 2003).

10 These six variables are linked to each other and orbital position via physical and biological mechanisms that are represented by the four proxy variables. $F e$ is derived almost entirely from terrestrial sources and proxies changes in atmospheric circulation and a so-called iron fertilization effect, which may enhance the biotic uptake of $\mathrm{CO}_{2}\left(\mathrm{Martin}_{\text {, }}\right.$ 1990). Sulfate $\mathrm{SO}_{4}$ originates mainly from marine biogenic emissions of dimethylsulphide (after removing sea-salt sources using the $\mathrm{Na}$ data), and so proxies marine biological activity (Cosme et al., 2005). It is included to represent

15 the possible effect of iron-containing dust on biological activity and/or the effect of biological activity on atmospheric $\mathrm{CO}_{2}$. Sea salt sodium $\mathrm{Na}$ is derived from the sea-ice surface and proxies the extent of winter sea-ice (Wolff et al 2003). It is included to represent the possible effect of sea ice on the flow of $\mathrm{CO}_{2}$ from the ocean to the atmosphere (Stephens and Keeling, 2000). Non sea-salt calcium $\mathrm{Ca}$ has a terrestrial origin (mainly Patagonia) and may represent changes in temperature, moisture, vegetation, wind strength, glacial coverage, or changes in sea level in and around Patagonia (Basile et al., 1997), a locale thought to play an important role in glacial cycles.

To make these data amenable to a statistical analysis, we convert them to a common time scale (EDC3) using conversions from Parrenin et al., (2007) and Ruddiman and Raymo (2003). Unevenly spaced observations are interpolated (linearly) to generate a data set in which each series has a time step of $1 \mathrm{kyr}$ (Miller, 2019). To eliminate the effects on inverting matrices with elements that differ greatly in size (due to different units of measurement), each of the fourteen time series is standardized as follows:

$x_{i}=\left(y_{i}-\bar{y}\right) / \sqrt{\operatorname{Var}(y),} \quad t=1, \ldots, 391$

where $y_{t}$ is the value (in original units), $\bar{y}$ is the average value over the in-sample period, and $\operatorname{Var}(y)$ is the variance over the in-sample period.

\subsection{Simulating the CVAR Model}

The equations used to estimate the CVAR model in KJ2013 are given by:

$\Delta x_{t}=A_{0} \Delta w_{t}+A_{1} \Delta w_{t-}+\Gamma_{1} \Delta x_{t}+\Pi z_{t-1}^{\prime}+\varepsilon_{t}$

in which $x_{t}$ is a $10 \times 1$ vector that includes the ten endogenous variables; Temp, $\mathrm{CO}_{2}, \mathrm{CH}_{4}, \mathrm{Ice}, \mathrm{Fe}, \mathrm{Na}, \mathrm{Ca}, \mathrm{SO}_{4}$,

35 Level, and SST; $w_{t}$ is a $4 \times 1$ vector that includes the four exogenous variables Ecc, Prec, Obliq, and SunsumS; $z^{\prime}=$ $\left[x_{t}^{\prime}, w_{t}^{\prime}, 1\right], \Gamma_{1}, A_{0}, A_{1}$, are $10 \times 14$ matrices of short-run coefficients; $\Pi$ is a $10 \times 15$ matrix of long-run coefficients, 
$\Delta$ is the first difference operator $\left(\Delta x_{t}=x_{t}-x_{t-1}\right), \varepsilon_{i}$ is an error term with mean value zero and variance $\Omega$ that is normally, independently, and identicially distributed.

The condition that the conditional process $\left(x_{t} \mid w_{t}\right)$ is nonstationary is formulated as a reduced rank hypothesis on the matrix $\Pi$

in which $\alpha$ is a $10 \times r$ matrix of coefficients, which describe the rate at which the ten climate variables adjust back towards equilibrium after the system has been pushed away by exogenous shocks (i.e. changes in orbital geomtery); $r$ is the number of cointegration relations given by the reduced rank of the $\Pi$ matrix; and $\beta$ is a $r \times 15$ matrix of cointegration coefficients that define the $r$ stationary deviations from long-run equilibrium relationships, the so called cointegration relations, $\beta^{\prime} z_{t}$. Maximum likelihood estimates for the elements of the $\beta$ and $\alpha$ matrices as reported by KJ 2013 are given in section II of the Supplemental Material. The model in KJ2013 is estimated as a partial system (Johansen 1992, Harbo et al., 1998, Juselius 2006) where orbital variables are weakly exogenous.

Here we simulate the estimated model model over the full time period using a dynamic simulation in an open model, conditioned on the (strongly) exogenous orbital variables $w_{t}$ (equivalent to a dynamic forecast). To simulate climate during the in- and out-of-sample periods, the ten endogenous variables $x$ are expressed as a function of the exogenous solar variables and shocks to the climate system by inverting Equation (2) into the moving average form:

$x_{t}=C \sum_{i=1}^{t} \varepsilon_{t}+C^{*}(L) \varepsilon_{t}+C_{w} w_{t}+C_{w}^{*}(L) \Delta w_{t}$ where $C=\beta_{\perp}\left(1-\Gamma_{1}\right)^{-1} \alpha_{\perp} ; \quad \alpha_{\perp}$ is a $10 \times(10-r)$ matrix orthogonal to $\alpha$ describing the stochastic trends and $\beta_{\perp}$ is a $10 \times(10-r)$ matrix orthogonal to $\beta$ determining how the stochastic trends load into the climate variables; $L$ is the lag operator (for example, $L \varepsilon_{t}=\varepsilon_{t-1}$ ); $C^{*}(L)$ and $C_{w}^{*}(L)$ are stationary lag polynomials; $C_{w}$ is $10 \times 4$; and the matrices are functions of the parameters $\left(A_{0}, A_{1}, \Gamma_{1}, \alpha, \beta\right)$. Based on the ten cointergating relations reported by $\mathrm{KJ} 2013$ $r=10$, then $C=0$, the in- and out-of-sample simulations are based on model (2) subject to (3) by setting $\varepsilon_{t}=0$ which implies that the simulated variables, $\hat{x}_{t}$, are calculated from the exogenous drivers, $C_{w} w_{t},\left(A_{0} \Delta w_{t}\right)$, the dynamics attached to them, $C_{w}^{*}(L) \Delta w_{t-1},\left(A_{1} \Delta w_{t-1}\right)$, and the internal climate dynamics $C^{*}(L) \varepsilon_{t}\left(\Gamma_{1} \Delta \hat{x}_{t-1}, \alpha \beta^{\prime z t-1}\right)$.

25 The out-of-sample simulation is generated by allowing the model to 'spin up' between $800 \mathrm{kyr}$ BP and $792 \mathrm{kyr}$ BP, which enables the endogenous variables to converge towards the values that are implied by the exogenous conditioning variables (Prec, Ecc, Obl, and SunSumS). During this 'spin-up' period, the model is initialized using observed values for Temp, SST, and Ice, which are available starting $800 \mathrm{kyr}$ BP. The time series of $\mathrm{CO}_{2} \mathrm{CH}_{4}, \mathrm{Fe}, \mathrm{Na}, \mathrm{SO} 4, \mathrm{Ca}$, and Level have more recent start dates (Table 1). For these variables, the model is initialized with values that correspond to their sample mean. Once the model is spun-up, the model is run continuously through the present; values from 792 kyr BP through 392 kyr BP constitute the out-of-sample period. Values from 391 kyr BP through the present constitute the in-sample period.

\subsection{Statistical Measures of Model Performance}

We use RMSE as a simple heuristic to compare the model's predictive accuracy during the in- and out-of-sample periods. Because accuracy may vary over time, we use an indicator saturation technique [R-package gets Pretis et al., 2018; Castle et al., 2015] to identify periods during which the simulation significantly deviates from observations (i.e. simulation errors are statistically different from zero). Outliers refer to a statistically significant difference in the 
simulated value of variable $x$ relative to the observed value for a single time step, while persisting errors are statistically significant differences that persist for two or more consecutive time-steps. Outliers and persisting errors are evaluated for every possible time step. Here, we retain only those outliers or persisting errors that exceed the $p \alpha=0.001$ threshold. This tightly controls the false-positive rate of detected periods of model failure. The method used to identify outliers and persisting errors are summarized in Supplementary Section III. This approach is used to assess the time-varying performance of climate models (Pretis et al., 2015), the forecast accuracy of economic predictions (Ericsson 2017), as well as to detect volcanic eruptions in temperature reconstructions in both simulated climate data (Pretis et al., 2016) and proxy-reconstructions (Schneider et al., 2017).

\subsection{Identifying Periods of Simulation Failures}

If model performance does not change over time, we expect outliers and persisting errors to occur randomly throughout the sample and be equally likely in each sub-sample. We use this assumption to compare the distribution of outliers and persisting errors between in-sample and out-of-sample periods and among nineteen marine isotope stages. For each thousand-year time step, we count the number of variables that exhibit an outlier or persisting error. Following this procedure, the maximum number of outliers or persisting errors for any single time-step is ten. These sums (and values for individual variables) are assigned to the in- or out-of-sample period or individual marine isotope stages.

To evaluate the distribution of outliers and persisting errors between the in- and out-of-sample periods and among marine isotope stages, we test whether their occurrence is different from a uniform random distribution (expected under the null-hypothesis of equal performance) using a Pearson chi-square test (P), which is calculated as follows:

$P=\sum_{j=1}^{n} \frac{\left(o_{j}-E_{j}\right)^{2}}{E_{j}}$

in which $n$ is the number of periods ( $\mathrm{n}=2$; in-sample $j=1$; out-of-sample $j=2$; or nineteen marine isotope stages), $O_{j}$ is the number of outliers or persisting errors that are identified in period $j$, and $E_{j}$ is the number of occurrences expected in period $j$.

The number of occurrences expected in period $j\left(E_{j}\right)$ is calculated based on the null hypothesis that outliers or persisting errors are distributed uniformly among periods. This null implies that the expected value $\left(E_{j}\right)$ can be calculated as:

$E_{j}=\frac{Y r_{j}}{\sum_{i}^{n} Y r_{j i}} \times \sum_{j=1}^{n} O_{j}$

in which $Y r$ is the number of thousand-year time steps in period $j$ for which observed values are available and $n$ is the number of periods for which observed values are available for the $791 \mathrm{kyr}$ simulation period. $P$ is evaluated against a $\chi^{2}$ distribution with n-1 degrees of freedom. If the test rejects the null hypothesis that outliers or persisting errors are distributed randomly among periods (i.e. some periods are simulated more/less accurately than others), the more accurate subsample is identified by the numerator of Equation (5) $\left(O_{j}-E_{j}\right)$. A negative value during the in-sample period $\left(\left(O_{1}-E_{1}\right)<0\right)$ would indicate that the number of outliers or persisting errors detected during the in-sample period is less than expected by a uniform random distribution. This result would suggest that the model generates a more accurate simulation during the in-sample period. Equations (5) and (6) also are used to test whether outliers or persisting errors are distributed randomly across the nineteen marine isotope stages $(n=19)$ that fall within the $791 \mathrm{kyr}$ simulation. The first observation is $791 \mathrm{kyr}$ BP, which falls in MIS 19. 


\subsection{Causes for Model Failure}

To evaluate the cause(s) for model failure, we test whether poor performance 'starts' with a specific variable(s) and whether this failure is communicated to the other variables through long- and short-run relations among endogenous variables. To identify the variable(s) that initiates the poor performance, we formalize techniques that are used by previous analyses. Previous analyses estimate a regression equation that specifies a dependent variable as a function of lagged values for an independent variable thought to 'precede' the dependent variable. For example, Li et al., (1998) conclude that $\mathrm{CO}_{2}$ 'precedes' $\delta^{18} O$ based on regression results that indicate $\delta^{18} O$ is related to five lagged values of $\mathrm{CO}_{2}$.

But this approach is incomplete (from a statistical perspective) because it ignores the autocorrelation structure of the dependent variable. To account for this effect, we use a technique developed by Granger (1969) that is used to analyze relations among climate variables during the instrumental temperature record (e.g. Kaufmann and Stern, 1997; Stern and Kaufmann, 2014). For this application, we estimate the following regression:

$15 \varepsilon_{i, t}=\alpha+\sum_{i=1}^{10} \sum_{j=1}^{S} \phi_{i, j} \varepsilon_{i, t-j}+\sum_{i=1}^{10} \sum_{j=1}^{S} D_{i, t-j} \theta_{i, j} \varepsilon_{i, t-j}+\sum_{j=0}^{S} \pi_{j} \omega_{i, t-j}+\eta_{i, t}$

in which $D_{i, t}$ is an indicator variable that equals one if the simulation error for variable $i$ during period $t$ is statistically different from zero (i.e. $\varepsilon_{i, t}$ is a persisting error) ( $D_{i, t}=0$ otherwise), $\eta$ is an error term (assumed to be normally distributed), and $\alpha, \phi, \theta, \pi$, are regression coefficients that are estimated using ordinary least squares. The number of lags (s) is determined using the Akaike Information criterion (Akaike, 1973). Equation (7) is estimated ten times, once with the simulation error for each endogenous variable on the left-hand side. We expect the coefficients $\phi_{i}$ generally to be statistically different from zero because simulation errors generally are correlated across variables, however, we are interested whether during the periods of simulation failure (as given by $D_{i, t}=1$ ), persisting errors for other endogenous variables propagate through the system, pre-dating/predicting persisting errors in the endogenous climate variable being modelled. Because the level of significance of selection in the first stage $\left(p_{\alpha} \simeq 0.001\right)$ makes falsepositives in $D_{i, t}$ unlikely (approximately 1 outlier to be expected spuriously on average), the detection of breaks in the first stage probably has little effect on tests on $\mathrm{D}_{\mathrm{i}, \mathrm{t}}$ in this second stage. We repeat this process without the simulation errors for sea level because the first observation for sea level (462 kyr BP) is much more recent than the other time series (Table 1), which limits the sample range when all ten simulation errors are analyzed using Equation (7).

For each simulation error for variable i ( $\left.\varepsilon_{i}\right)$, we estimate Equation (7) ten times. In each, we eliminate the simulation errors for one of the ten endogenous variables interacted with its non-zero mean simulation dummy $\sum_{j=1}^{S} D_{i, t-j} \theta_{i, j} \varepsilon_{i, t-j}$. This restriction is evaluated using an F-statistic that tests the null hypothesis that the persisting errors for the endogenous variable eliminated from Equation (7) have no information about the dependent variable beyond the additional variables included. These variables include the lagged values of simulation errors, the persisting simulation errors for the other endogenous variables, and the four exogenous variables for orbital geometry. Rejecting this null hypothesis allows us to state that the model's inability to simulate the endogenous variable that is eliminated from Equation (7) (as indicated by persisting errors) precedes the simulation errors for the endogenous climate variable on the left-hand side of Equation (7). 


\section{Results}

\subsection{Model Performance}

5

For both the in- and out-of-sample periods, Figure 1 suggests that the model generally captures the timing and magnitude of persistent changes in climate that are described by glacial cycles, which frequently are summarized by changes in land ice volume (Ice). For this variable, the model generally simulates the timing and magnitude of glaciations and terminations, including the gradual accumulation of ice and its rapid ablation (i.e. the saw-tooth

10 pattern). Furthermore, there are no skipped obliquity/precession beats (other than MIS 11). Finally, the model's ability to simulate glacial cycles during the out-of-sample period is inconsistent with speculation that the CVAR model's ability to reproduce the ten climate/physical variables during the in-sample period simply reflects the model's ability to reproduce the data used to estimate the coefficients. Instead, the ability of the model to simulate climate during the out-of-sample period suggests that its coefficients capture relations among orbital geometry and the ten climate/physical proxies that govern the climate system beyond the sample period.

\subsubsection{In- vs. Out-of-Sample Comparisons}

The similarity between the model's accuracy in- and out-of-sample (Figure 1) is consistent with comparisons of root mean square error (Figure 2). As expected, the RMSE for the out-of-sample period generally is larger than the RMSE for the in-sample period. But much of this increase is associated with MIS 11, most of which occurs during the outof-sample period (Figure 1). If we eliminate MIS 11 from the out-of-sample period, the RMSE of the in- and out-ofsample periods are similar (Figure 2). The outsized effect on the RMSE for the out-of-sample period is consistent with the 'stage 11 paradox.'

25 Tests indicate that we cannot reject the null hypothesis that outliers are distributed randomly between the in- and outof-sample periods (Table 2). A test statistic $\chi^{2}(1)=0.09$ fails to reject $(p>0.76)$ the null hypothesis that as a group, outliers for the ten climate/physical variables are distributed randomly between the in- and out-of-sample periods. Conversely, a test statistic $\chi^{2}(1)=52.5$ rejects $(p<0.001)$ the null hypothesis that as a group, persisting errors for the ten climate/physical variables are distributed randomly between the in- and out-of-sample periods.

\subsubsection{Comparisons Among Marine Isotope Stages}

Outliers and persisting errors are not distributed randomly among the nineteen marine isotope stages (Figure 3, Table 2). This result is generated in part by the 'stage 11 paradox.' If this stage is eliminated from consideration, we cannot

35 reject the null hypothesis that outliers for variables other than methane are distributed randomly among the remaining eighteen stages. Similarly, the RMSEs across variables are very similar in and out-of-sample when MIS 11 is excluded (Figure 2). Conversely, the number of persisting errors is not distributed randomly among the nineteen marine isotope stages, even if errors in MIS 11 are excluded (Table 2). 


\subsection{Causes for Model Failure}

Applying the $\mathrm{p}=0.05$ threshold to the tests that evaluate restrictions on Equation (7), sixteen of the one hundred tests reject the null hypothesis that lagged values for persisting errors (interacted with the non-zero dummy variable D) have no information about current values for the simulation errors on the left-hand side of Equation (7) beyond the right-hand side variables that remain in Equation 7 (Table 3). For the eighty-one tests run on the nine endogenous variables (other than sea level), the null is rejected eleven times (Table 4). In both cases, the number of rejections observed is greater than the number expected due to repeated testing at $\mathrm{p}=0.05$, five and four rejections, respectively. Together, these results suggest that the test results reveal information about the statistical ordering of simulation errors.

\section{Discussion}

\subsection{Nonlinearties and/or threshold effects drive the timing and magnitude of glacial cycles}

A recent review of terminations states "Terminations clearly represent a strongly nonlinear response to regional changes in the seasonality of solar radiation (Past interglacials Working Group of Pages, 2016)." We test this statement by using the CVAR to evaluate hypotheses about the importance of thresholds (e.g. Paillard, 1998; 2001; Ganopolski et al., 2016; Tzedakis, et al., 2017), nonlinearities (e.g. Tziperman et al., 2006), or governing equations that vary by phase of the glacial cycle. If any of these play an important role, the CVAR model, which does not include their effects, will not be able to simulate glacial cycles.

20 The CVAR model is largely linear. Both long- and short-run relations among variables are linear. The only non-linear relation is given by the fractional rate at which variables adjust to disequilibrium in the long-run relations $(\alpha)$. But this nonlinearity is constrained by the fact that the fractional rate of adjustment is constant and applies during all phases of the glacial cycle.

Despite its largely linear specification, the CVAR generally simulates the timing and magnitude of changes in ice volume (and other variables) without any skipped beats other than stage 11. Furthermore, this linear specification allows the model to simulate the saw-tooth pattern by which ice volume builds slowly but melts rapidly. These results suggest that non-linear relations, thresholds, or changes in governing equations are not important drivers of glacial cycles. This suggestion does not reject their presence, rather, Occam's razor implies that nonlinearities, threshold effects, and/or phase-specific governing equations are not needed to simulate important aspects of glacial cycles.

30 Furthermore, the CVAR's ability to simulate climate during the out-of-sample period is inconsistent with the hypothesis that "glacial cycles would exist even in the absence of the insolation changes (Tziperman et al., 2006)." If glacial cycles exist independently of changes in orbital geometry, a statistical model that is conditioned only on orbital geometry and spun up with no memory of previous cycles would not be able to simulate glacial cycles accurately during the initial out-of-sample period. As in Gonapolski and Calov (2011), the ten variables come to an equilibrium

35 and do not change thereafter if orbital geometry is held constant. Furthermore, the accuracy of the out-of-sample simulation is inconsistent with the argument that changes in solar insolation account for less than 20 percent of the variance in glacial temperature records (Wunsch, 2004). 


\subsection{The Mid Brunhes Event}

The demarcation between the in- and out-of-sample period (391 kyr BP) falls close to the Mid-Brunhes event, MBE (Jansen et al., 1986). Compared to the in-sample period used to estimate KJ2013, the pre-MBE out-of-sample period has; (1) lower concentrations of $\mathrm{CO}_{2}$, (2) glacial cycles with a smaller amplitude, and (3) cooler but longer interglacial periods (EPICA, et al., 2004; Luthi et al., 2008; Hoenisch et al., 2009). These three changes beg the question, do they represent a change in the dynamics that drive glacial cycles and/or a change in the drivers of glacial cycles. The latter is supported by Yin (2013), who concludes, "through a set of internal mechanisms insolation alone induces a systematic difference between the interglacials before and after the $430 \mathrm{kyr}$ ago in some ocean processes that are critical for the carbon cycle." Conversely, Tzedakis et al., (2009) argue 'astronomical forcing alone cannot explain the difference in interglacial intensity before and after the MBE."

Our model simulations contradict the latter, that the MBE represents a change in the dynamics that drive glacial cycles. As indicated in Figure 1, the single set of relations among orbital geometry and the climate system embodied in the CVAR model simulates the different characteristics of glacial cycles before and after the MBE. As such, the MBE is not a transition between regimes; rather there is something unique about the MBE in particular and MIS 11 in general.

\subsection{Mechanisms for the Stage 11 Paradox}

Imbrie et al., (1993) describe 'the stage 11 paradox' as a significant mismatch between orbital position and changes in climate associated with MIS 11 in general and termination V (430 -415 kyr BP) in particular. The latter is defined by the maximum in benthic $\delta^{18} O$ of MIS 12 and the benthic $\delta^{18} O$ plateau of MIS 11 (Broecker and van Donk, 1970). These periods are unique: Termination $\mathrm{V}$ is the longest of any during the previous half million years (Berger and Loutre, 1996; Droxler et al., 2003; Loutre and Berger, 2003; McManus et al., 2003; EPICA Community Members, 2004; Rohling et al., 2010; Liseicki and Raymo, 2005; Ruddiman, 2007). MIS 11 also is the longest period of prolonged, stable warm climate in the North Atlantic (Oppo et al., 1998; McManus et al., 1999; 2003). Finally, many areas have air and sea surface temperatures that reach values consistent with interglacial periods even though large areas of the Earth's surface are covered by ice (Ruddiman, 2007). Despite these large changes in climate, the changes in orbital geometry are small.

Consistent with this seeming mismatch, the CVAR model does a poor job of simulating termination $\mathrm{V}$ in particular

30 and MIS 11 in general. Figures 1-3 indicate that MIS 11 has more variables with persisting errors than any other period, either in- or out-of- sample (as well as driving the higher RMSE out-of-sample). This indicates MIS 11 is a prolonged period during which the model is not able to use the four variables for orbital geometry to simulate climate, which is the definition of the 'stage 11 paradox.'

\subsubsection{Difficulties in orbital tuning}

The CVAR's model's poor performance during MIS 11 could be caused by difficulties in orbital tuning. The insolation peak for MIS 11 occurs in the middle of the warm stage therefore, orbital tuning delays the interglacial peak in $\delta^{18} O$ compared to other stages (Candy et al., 2014; Imbrie et al., 1984; Liseicki and Raymo, 2005). Furthermore, MIS 11 
contains fewer tie points that can be used to anchor the chronology (Desprat et al., 2005), which means that the orbitally tuned chronology of MIS 11 is less secure than other warm stages (Candy et al., 2014). As such, the model's failure during this period may simply represent the poor quality of the chronology to which the simulation is compared. To evaluate whether the stage 11 paradox is an artifact of the poor quality of the chronology, we condition the model on some of the endogenous variables that are thought to play an important role in glacial cycles. Conditioning a model on observed values for one or more endogenous variables always will improve performance (Oreskes et al., 1994), but the variable used to condition the model will have little effect on model performance if the model's poor performance during MIS 11 is caused by the poor quality of the chronology because no endogenous variable will have more/less information about the poor chronology. Contrary to this expectation, model performance during stage 11 depends on the variable used to condition the model. Conditioning the model on observed values of $\mathrm{CO}_{2}$ or $\mathrm{Na}$ allows the model to simulate more of the decline in Ice (and more accurately simulate other variables) throughout MIS 11, including termination V (Figure 4). Conversely, conditioning the model on observed values for SST, which is thought to play an important role in MIS 11 (see below), does not improve the model's ability to simulate the interglacial in MIS 11. Although this failure may be explained by stronger latitudinal or meridional gradients in sea surface temperature (Kandiano et al., 2012), large variations in accuracy that depend on the endogenous variable used to condition the model suggest that the model's failure during MIS 11 is not caused solely by weaknesses in orbital tuning.

\subsubsection{Mechanistic Explanations}

The mechanisms and sequences that generate the 'stage 11 paradox' cannot be fully identified by the CVAR model because it greatly simplifies physical relations and it has a relatively coarse temporal resolution (1 kyr). Conversely, its ability to accurately simulate glacial cycles (except MIS 11) using orbital position alone allows the CVAR model to test competing hypotheses about the 'stage 11 paradox' by identifying exceptions to the model sequences that accurately simulate terminations other than termination V. In other words, the statistical ordering of simulation errors allows us to identify what is unique about MIS 11 (and termination V) and whether these differences play an important role.

Explanations for terminations in general - and stage 11 in particular - share several components. Many start with a change in meridonal overturning circulation and a bipolar seesaw that create a negative correlation between changes in hemispheric temperatures. Specifically, terminations may start with changes in orbital position that add freshwater to the North Atlantic, this freshwater melt slows Atlantic meridonal overturning circulation (Elliot et al., 2002; McManus et al., 2004; Oppo et al., 1995; Vidal et al., 1997), and this slowdown creates a nearly simultaneous change in sea surface temperatures in the Southern Hemisphere via the bipolar seesaw (Barker et al., 2009; Broecker 1998; 1986; Schmittner et al., 2002; Stocker and Johnson, 2003). In addition to an opposite change in sea surface 35 temperature, there is evidence that changes in buoyancy (Watson and Garabato, 2006), latitudinal shifts in the Westerlies (Anderson et al., 2009; Ninnermann and Charles, 1997; Toggweiler et al., 2006), and/or a changes in sea ice (Stephens and Keeling, 2000) affect the flow of $\mathrm{CO}_{2}$ from the southern Ocean, which is an important reservoir for glacial/interglacial $\mathrm{CO}_{2}$ (Knox and McElroy, 1984; Sarmiento and Togeweiler, 1984; Seigenthaler and Wenk, 1984; Anderson et al., 2009; Skinner et al., 2013). 
Uncertainties about this general schema include questions about the role of changes in sea surface temperature relative to the location of the Westerlies/sea ice and the role of $\mathrm{CO}_{2}$ from the Southern Ocean; does ventilation drive deglaciation or is it caused by the glaciation? Riveiros et al., (2013) postulate that termination V is driven "primarily via meridonal heat transport anomalies that would have enhanced the incipient warming arising from relatively weak insolation forcing and only secondarily via $\mathrm{CO}_{2}$ release." Conversely, Andersen et al., (2009) show that changes in the position of the Westerlies are the main driver for the increased flow of $\mathrm{CO}_{2}$ to the atmosphere during the termination of the last ice age. Similarly, a shift by the Westerlies precedes the drop in atmospheric $\mathrm{CO}_{2}$ during MIS 5 (Govin et al., 2009).

These competing hypothesis for terminations in general and stage 11 in particular can be tested by the statistical ordering of the model errors. If changes in sea surface temperature initiate Termination V, the model's inability to simulate termination V will 'start' with its inability to simulate SST. This inability will be indicated by simulation errors for SST that precede and have information about the simulation errors for other variables. Specifically, simulation errors for other variables, such as $\mathrm{CO}_{2}$, will not have prior information about the errors for SST and these errors will have prior information about the errors for the other variables, such as $\mathrm{CO}_{2}$.

15 The statistical ordering of simulation errors indicates that the simulation errors for SST do not precede the model's inability to simulate MIS 11 and termination V. Errors for SST are preceded by the persisting errors for other variables (read across the SST row in Tables 3 and 4), such as $\mathrm{CO}_{2}$, and the persisting errors for $S S T$ do not have prior information about the simulation errors for any variables (read down the SST column) at $p \leq 0.05$. Using a threshold $p \leq 0.10$, there is some evidence that persisting errors for SST have information about Ice. Consistent with these results, conditioning the model on SST, which eliminates the simulation errors for SST, does not improve the model's ability to simulate Ice during MIS 11 relative to other potential causes for the stage 11 paradox (Figure 4). In toto, these results suggest that model failures do not 'start with' an inability to simulate sea surface temperature; rather the failure to simulate sea surface temperature is caused by the inability to simulate some other variable(s). As such, changes in sea surface temperature probably are not ultimately responsible for the 'stage 11 paradox.'

25 Instead, the statistical ordering generated by Equation (7) highlights the importance of the model's inability to simulate atmospheric carbon dioxide. Reading across the $\mathrm{CO}_{2}$ row indicates that the simulation errors for other variables, including SST have no prior information about the simulation errors for $\mathrm{CO}_{2}$, which suggests that model failures 'start with' an inability to simulate carbon dioxide. Furthermore, these failures propagate through the system. Reading down the $\mathrm{CO}_{2}$ column indicates that the persisting errors for $\mathrm{CO}_{2}$ have information about the simulation errors for other variables including Ice and SST (Table 4).

The importance of carbon dioxide is consistent with results that indicate conditioning the model on observed values of $\mathrm{CO}_{2}$ improves (compared to conditioning the model on SST) the model's ability to simulate Ice during MIS 11 (Figure 4). This supports the argument that high concentrations of $\mathrm{CO}_{2}$ are responsible for the warm interglacial during MIS 11 (Yin and Berger, 2012). Together, these results suggest that terminations in general, and termination V in particular, are driven by changes in atmospheric carbon dioxide. Furthermore, they are consistent with the notion that the peak in $\mathrm{CO}_{2}$ concentrations drive changes in the glacial cycle that occur after $450 \mathrm{kyr}$ BP (Pages, 2016). On the other hand, they contradict the notion that changes in carbon dioxide are a positive feedback loop in the Earth system, as opposed to a cause of glacial terminations (Ganopolski and Calov, 2011). 
But the model's inability to simulate MIS stage 11 may not start solely with an inability to simulate $\mathrm{CO}_{2}$. Persisting errors for Ice also are preceded by persisting errors for $\mathrm{Ca}$ and $\mathrm{Fe}$ (proxies for wind strength and aridity Section 2.1 and Supplemental Section I). And the persisting errors for $\mathrm{Ca}$ are preceded by the persisting errors for $\mathrm{Na}$ (a proxy for sea ice in the southern ocean Section 2.1 and Supplemental Section I) Although results cannot resolve the timing of the model's inability to simulate wind $(\mathrm{Ca}, \mathrm{Fe})$ and sea ice $(\mathrm{Na})$, their importance suggests that the model's inability to simulate the long interglacial of MIS 11 is generated in part by the model's inability to simulate the location and strength of winds, the extent of sea ice, and/or the ventilation of $\mathrm{CO}_{2}$ from the Southern Ocean.

\section{Conclusion}

Our model is able to accurately simulate entire glacial cycles for an out-of-sample period that does not prescribe GHG forcing: the simulation is driven only by changes in orbital geometry. This ability suggests that the model can accurately hindcast climate using known climate parameters, which is the criterion proposed by Tzedakis et al., (2009) for understanding the current climate and where it is headed. Although satisfying this criterion has to be interpreted with caution because predictability is not necessarily informative about the quality of a model with respect to capturing underlying causality (see e.g. Oreskes et al., 1994, or Clements and Hendry, 2005), the ability to hindcast climate suggests that our model could supplement the search for analogues for the Holocene (11,700 years before the present through the present), many of which focus on MIS 11 (Droxler et al., 2003; Tzedakis, 2010; Pol et al., 2011). Despite some similarities, our results suggest that such efforts are fraught with difficulty. Most importantly, the statistical model cannot use the four measures of orbital geometry to simulate the depth and length of the interglacial that is associated with MIS 11. Conversely, the model is able to simulate many aspects of the current warm period (Figure 1 \& 3): notable exceptions include peristing errors associated with Ice and SST (see below). This implies that any similarity in orbital geometry and feedback mechanisms (Imbrie et al., 1992; 1993, Ruddiman 2003; 2006) do not automatically translate into similar climates. As such, there probably are important differences between the Holocene and MIS 11.

Ironically, the interglacials during MIS 11 and the Holocene may share an important similarity: an important role for carbon dioxide. The inability to simulate the interglacial in MIS 11 is likely caused by a poorly-modelled physical mechanism that raises atmospheric carbon dioxide. It is highly unlikely that this mechanism is related to human activity, even though MIS 11 contains the first evidence for the use of fire by people in Britain (Gowlett, 2005; Preece et al., 2006). Conversely, others argue that Holocene warming is amplified by anthropogenic emissions of carbon dioxide and methane (Ruddiman 2003; 2005; 2007).

Rather than trying to decide which aspects of the paleoclimate record 'line up' across marine isotope stages (e.g. Candy et al., 2014), future efforts will use the statistical model to identify the cause(s) for the current warming and how long it will last. Specifically, we will compile future values for orbital geometry and use them to simulate the model as a CVAR-based alternative to GCM-based simulations (see e.g. Ganopolski et al., 2016). These CVAR simulations also will be used to assess the early Anthropogenic hypothesis by evaluating the degree to which anthropogenic emissions of carbon dioxide and methane can account for outliers and persisting errors in Ice and other climate variables during the Holocene. 
Data and Code Availability: The data and computer code used in this analysis are available on OpenBU, which is FAIR-compliant, and can be accessed through a globally unique and eternally persistent identifier, https://hdl.handle.net/2144/40340 P. This dataset is distributed under the terms of the Creative Commons Attribution-ShareAlike 4.0 License (http://creativecommons.org/licenses/by-sa/4.0).

Team list: The team includes Robert Kaufmann (RK) and Felix Pretis (FP).

Author contributions: This project was conceived by RK and FP. RK compiled the data from the statistical model and FP did the statistical analysis to identify impulses and steps. RK and FP write the manuscript, designed the tables, and created the figures together.

Competing Interests: The authors have no financial or non-financial interests associated with the material in this manuscript.

Acknowledgements: We thank David F Hendry, Luke Jackson, and Katarina Juselius for helpful comments and suggestions. Financial support from the Robertson Foundation and British Academy is gratefully acknowledged."

\section{References}

20 Akaike, H.: 2nd International Symposium on Information Theory, P.N. Petrov and F. Csaki, Eds., Akadacemiai Kiadaco, 267-281, 1997.

Anderson, R.F., Ali, S., Bradtmiller, L.I., Nielsen, S.H.H., Fleisher, M.Q., Anderson, B.E., and Brickle, L.H.: Wind driven upwelling in the southern ocean and the deglacial rise in atmospheric $\mathrm{CO}_{2}$, Science, 323:1443-1448, 2009.

Archer D., Winguth, A., Lea, D., and Mahowald N.: What caused the glacial/interglacial atmospheric pCO(2) cycles? Rev. Geophys. 38(2), 159-189, 2000.

Barker, S., Diz, P.,Vautravers, J., Pike, J., Knorr, G., Hall, I.R., and Broecker W.S., Interhemispheric Atlantic seesaw response during the last deglaciation, Nature 457:1097-1102, 2009.

Basile, I., Grousset, F.E., Revel, M., Petit, J.R., Biscaye, P.E., and Barkov, N.I.: Patagonian origin of glacial dust deposited in East Antarctica (Vostok and Dome C) during glacial stages 2, 4 and 6, Earth and Planetary Science Letter, 146,573-589, 1997.

Berger, A., and Loutre, M. F.: Modelling the climate response to astronomical and $\mathrm{CO}_{2}$ forcings, C. R. Acad. Sci., Ser. IIa: Sci. Terre Planetes,323(1), 1-16, 1996.

Broecker, W.S.: Paleocean circulation during the last deglaciation: a bipolar seesaw? Paleoceanography 13:119-121, 1998.

35 Broecker, W.S., and vanDonk, J.: Insolation changes, ice volumes, and O-18 record in deep-sea cores, Reviews of Geophysics and Space Physics: 8(1):169, 1970.

Brovkin, V., Ganopolski, A., Archer, D., and Munhoven, G.: Glacial $\mathrm{CO}_{2}$ cycle as a succession of key physical and biogeochemical processes. Climate of the Past, 8(1), 251-264, 2012.

Candy, I., Schreve, D.C., Sherriff, J.,Tye, G.J.: Marine isotope stage 11: paleoclimates, paleoenvironments, and its role as an analogue for the current interglacial, Earth Science Review, 128:17-51, 2014.

Castle, J.L., Doornik, J.A., Hendry, D.F., and Pretis, F.: Detecting location shifts during model selection using stepindicator saturation. Econometrics, 3, 240-264, 2015

Chappell, N., and Shackleton, N.J.: Oxygen isotopes and sea level, Nature 324: 137-140, 1986. 
Clements, M. P., \& Hendry, D. F.: Evaluating a model by forecast performance. Oxford Bulletin of Economics and Statistics, 67(s1), 931-956, 2005.

Cosme, E., Hourdin, F., Genton, C., and Martinerie, P.: Origin of dimethylsulfide, non-sea-salt sulfate, and methanesulfonic acid in eastern Antarctica, Journal of Geophysical Research, 110, 2005.

Davidson, J. E., Stephenson, D. B., and Turasie, A. A.: Time series modeling of Paleoclimate data. Environmetrics, 27(1), 55-65, 2016.

Desprat, S., Sanchez-Goni, M.F., Turon, J.L., McManus, J.F., Loutre, M.F., Deprat, J., Malaize, B., Peyron, O., Peypouquet, J.P.: Is vegetation responsible for glacial inception during periods of muted isolation changes, Quat. Sci. Rev. 24:1361-1374, 2005.

10 Droxler, A., W., Alley, R. B., Howard, W. R., Poore, R. Z., and Burckle, L. H.: Unique and exceptionally long interglacial marine isotope stage 11: Window into Earth warm future climate, in Earth's Climate and Orbital Eccentricity: The Marine Isotope Stage 11 Question, Geophys. Monogr. Ser., vol. 137, edited by Droxler, A. W., Poore, R. Z. and Burckle, L. H., pp. 1-14, AGU, Washington, D. C., 2003.

Elliot, M L. Labeyrie, and JC Duplessy, 2002, Changes in north Atlantic deep-water formation associated with the

15 Dansgaard-oechger temperature oscillations (60-10ka) Q. Sci. re. 21:1153-1165.

Engle, R.F., and Granger, C.W.J.: Cointegration and error correction: representation, estimation, and testing, Econometrica, 55(2), 251-276, 1987.

EPICA Community Members, Eight glacial cycles from an Antarctic ice core, Nature, 429, 623- 628, 2004.

Ericsson, Neil R. (2017). How Biased Are U.S. Government Forecasts of the Federal Debt? International Finance Discussion Papers 1189, 2017.

Fischer H. F., Fundel,F., Ruth U., et al, Reconstructions of millennial changes in dust emission, transport, and regional sea ice coverage using the deep EPICA ice cores from the Atlantic and Indian Ocean sector of Antarctica, Earth and Planetary Science Letters 260:340-354, 2007.

Ganopolski, A., and Calov, R.: The role of orbital forcing, carbon dioxide, and regolith in $100 \mathrm{kyr}$ glacial cycles,

Climate of the Past, 7:1415-1425,2011.

Ganopolski, A., Winkelmann, R., and Schellnhuber, H.J.: Critical insolation- $\mathrm{CO}_{2}$ relation for diagnosing past and future glacial inception, Nature 529: 7585: 200-U159, 2016.

Govin, A., Michel, E., Labeyrie, L., Waelbroeck, C., Dewilde, F., and Jansen, E. : Evidence for northward expansion of Antarctic Bottom Water mass in the Southern Ocean during the last glacial inception,

Paleoceanography, 24 PA1202, 2009.

Gowlett, J.A.J., Hallos, J., Hounsell, S., Brant, V., and Debenham, N.C.: Beeches Pit-archaeology, assemblage dynamics and early fire history of a Middle Pleistocene site in East Anglia, UK, J Eurasian Prehist, 3:3-40, 2005.

Granger, C.W.J.: Investigating causal relations by econometric models and cross spectral models. Econometrica 37:424-438, 1969.

35 Harbo, I., Johansen, S., Nielsen, B., and Rahbek, A.: Asymptotic inference on cointegrating rank in partial systems. Journal of Business \& Economic Statistics, 16(4), 388-399, 1998.

Hendry, D.: Dynamic Econometrics, Oxford: Oxford University Press, 1994.

Hendry, D., and Juselius, K.: Explaining cointegration analysis part 1 The Energy Journal 21:1-42, 2000. 
Hendry, D. and Richard, J.F.: On the Formulation of Empirical Models in Dynamic Econometrics, Journal of Econometrics, 20(1), 3-33, 1982.

Hoenisch, B., Gary, H.N., Archer, D., et al, Carbon dioxide concentrations across the Mid-Pleistocene Transition, Science 324:1551-1554, 2009.

Huybers, P.: Combined obliquity and precession pacing of late Pleistocene deglaciations, Nature 480: 229-232, 2012. Huybers, P., and Wunsch, C.: Obliquity pacing of the late Pleistocene glacial terminations, Nature, 434, 491-494, 2005.

Imbrie, J., Hays, J. D., Martinson, D. G., McIntyre, A., Mix, A. C., Morley, A. J., Paces, N. G., Prell, W. L., and Shackleton, N. J.: The orbital theory of Pleistocene climate: Support from a revised chronology of the marine 180

10 record, in Milankovitch and Climate. Understanding the Response to Astronomical Forcing, edited by A. L. Berger et al., pp. 607-611, D. Reidel, Dordrecht, 1984.

Imbrie, J., et al. On the structure and origin of major glaciation cycles 1. Linear responses to Milankovitch forcing, Paleoceanography, 7(6), 701-738, doi:10.1029/92PA02253, 1992.

Imbrie, J., Berger, A., Boyle, E.A., Clemens, S.C., Duffy, A., Howard,W.R., Kukla, G., Kutzbach, J., Martinson,

15 D.G.,McIntyre, A.,Mix, A.C., Molfino, B., Morley, J.J., Peterson, L.C., Pisias, N.G., Prell, W.L., Raymo, M.E., Shackleton, N.J., Toggweiler, J.R.:. On the structure and origin of major glaciation cycles. Part 2. The 100,000-year cycle, Paleoceanography 8:699-735, 1993.

Jansen, J.H.F., Kuijpers, A., and Troelstra, S.R., A Mid-Brunhes climatic event: long-term changes in global atmosphere and ocean circulation Science 750:619-622, 1986.

20 Johansen, S.: Cointegration in partial systems and the efficiency of single-equation analysis. Journal of Econometrics, 52(3), 389-402, 1992.

Juselius, K.: The cointegrated VAR model: methodology and applications. Oxford, Oxford University Press, 2006.

Kandiano, E.S., Bauch, H.A., Fahl, K., Helmke, J.P., Röhl, U., Pérez-Folgado, M., and Cacho, I., The meridonal temperature gradient in the eastern North Atlantic during MIS 11 and its link to the ocean-atmosphere system,

Palaeogeogr. Palaecoclimatol. Paleoecol. 333-334: 24-39, 2012.

Kaufmann, R.K., and Juselius, K.: Testing hypotheses about glacial cycles against the observational record,

Paleoceanography 28, 1-10, doi:10.1002/palo.20021, 2013,

Kaufmann, RK and Juselius, K.: Testing Competing Forms of the Milankovitch Hypothesis: A Multivariate Approach, Paleoceanography. 31, doi:10.1002/2014PA002767, 2016.

30 Kaufmann, R.K., and Stern, D.I.: Evidence for human influence on climate from hemispheric temperature relations. Nature 388:39-44, 1997.

Keeling, R.G.. and Stephens, B.B.: Antarctic sea ice and the control of Pleistocene climate instability, Paleoceanography, 16(1) 112-131, 2000.

Knox, F, and McElroy, M.B.: Changes in atmospheric $\mathrm{CO}_{2}$ - Influence of the marine biota at high latitude, J. Geophys.

Li, X.S., Berger, A., and Loutre, M.F., $\mathrm{CO}_{2}$ and Northern Hemipshere ice volume variations over the middle and Quaternary, Climate Dynamics, 14:537-544, 1998.

Lisiecki, L. E., and Raymo, M. E,: A Pliocene-Pleistocene stack of 57 globally distributed benthic D18O records, Paleoceanography, 20, 1-17, 2005. 
Lisiecki, L.E.: Links between eccentricity forcing and the 100,000-year glacial cycle, Nature Geoscience 3(5), SI: 349-352, 2010

Loutre, M. F., and Berger, A.: Marine Isotope Stage 11 as an analogue for the present interglacial, Global Planet. Change, 36(3), 209-217, 2003.

Luthe, D., Floch, M. L., Bereiter, B., Blunier, T., Blunier, J.M., Barnola, J.M., Siegenthaler, U., Raynaud, D., Jouzel, J., Fischer, H., Kawamura, K., and Stocker, T. F.: High-resolution carbon dioxide concentration record 650,000800,000 years before present, Nature, 453, 379-382, 2008.

Martin, J.H.: Glacial-interglacial $\mathrm{CO}_{2}$ change: the iron hypothesis, Paleoceanography 5:1-13, 1990.

Masson-Delmotte, V., Kageyama, M., Braconnot, P., Charbit, S., Krinner, G., Ritz, C., Guilyardi, E., Jouzel, J., AbeOuchi, A., Crucifix, M., Gladstone, R.M., Hewitt, C.D. , Kitoh, A., LeGrande, A.N., Marti, O., Merkel, U., Motoi, T., Ohgaito, R., Otto-Bliesner, B., Peltier, W.R., Ross, I., Valdes, P.J., Vettoretti, G., Weber, S.L., Wolk, F., and Yu, Y.: Past and future polar amplification of climate change: Climate model intercomparisons and ice-core constraints. Clim. Dyn., 26, 513-529, doi:10.1007/s00382-005-0081-9, 2006.

Masson-Delmotte, V., Stenni, B., Pol, K., Braconnot, P., Cattani, O., Falourd, S., Jouzel, J. Landais, A., Minister, B.,

15 Barnola, J., Chappellaz, J., Kinner, G., Johnsen, S., Rothlisberger, R., Hansen, J., Mikolajewicz, U., and Otto-Bliesner, B.: EPICA Dome C record of glacial and interglacial intensities, Quaternary Sci. Rev., 29, 113-128, 2010.

Miller, J.I.: Testing cointegrating relationships using irregular and non-contemporaneous series with an application to paleoclimate data, Journal of Time Series Analysis, DOI: 10.1111/jtsa.12469, 2019.

McManus, JF, Francois, R. Gheradi, J.M., Keigwin, L.D. and Brown-Leger, S.: Collapse and rapid resumption of Atlantic meridonal circulation linked to deglacial climate changes, Nature 428:834-837, 2004.

McManus, J. F., Oppo, D.W., and Cullen, J. L.: A 0.5-million-year record of millennial-scale climate variability in the North Atlantic, Science, 283, 971-975, 1999.

McManus, J., Oppo, D., Cullen, J., Healey, S.: Marine Isotope Stage 11 (MIS 11): analog for Holocene and future climate? In: Droxler, A.W., Poore, R.Z., Burckle, L.H. (Eds.), Earth's Climate and Orbital Eccentricity:

The Marine Isotope Stage 11 Question. AGU Geophysical Monograph Series No. 137, pp. 61-66, 2003.

Ninnermann U.S. and Charles, C:D.: Regional differences in Quaternary Subantarctic nutrient cycling: Link to intermediate and deep water ventilation, Paleoceanography 12:560-567, 1997.

Oppo, D.W., McManus, J.F., Cullen, J.L.: Abrupt climate events 500,000 to 340,000 years ago: evidence from subpolar North Atlantic sediments Science 279: 1335-1338, 1998.

30 Oppo, D.W., Raymo, M.E., Lohmann, G., Mix, A.C., Wright, J.D., and Prell, W.L.: A record of Upper North Atlantic deep water during the past 2.6 Myrs, Paleoceanography 10:395-404, 1995.

Oreskes, N., Shrader-Frechette, K., and Belitz, K.: Verification, validation, and confirmation of numerical models in the earth sciences. Science, 263(5147), 641-646, 1994.

Paillard, D., Labeyrie, L., and Yiou, P.: Macintosh program performs time-series analysis, Eos Trans. AGU, 77, 379, 1996.

Parrenin, F., Barnola, J.M., Beer, J., Blunier, T., Castellano, E., Chappellaz, J., Dreyfus, G., Fischer, H., Fujita, S., Jouzel, J., Kawamura, K., Lemieux-Dudon, B., Loulergue, L., Masson-Delmotte, V., Narcisi, B., Petit, J.-R., Raisbeck, G., Raynaud, D., Ruth, U., Schwander, J., Severi, M., Spahni, R., Steffensen, J. P., Svensson, A., Udisti, R., 
Waelbroeck, C., and Wolff, E.: The EDC3 chronology for the EPICA Dome C ice core, Clim. Past, 3, 485-497, https://doi.org/10.5194/cp-3-485-2007, 2007.

Past interglacials Working Group of Pages, Interglacials of the last 800,00 years, Rev. Geophys., 54,162-219, 2016.

Pol, K., Debret, M., Masson-Delmotte, V., Capron, E., Cattanii, O., Dreyfus, G., Falourd, S., Johnsen, S., Jouzel, J.,

Landais, A., Minster, B., Stenni, B.: Links between MIS 11 millennial and sub-millennial variability and long term trends as revealed by new high resolution EPICA Dome $\mathrm{C}$ deuterium data - a comparison with the Holocene Clim. Past 7:437-450, 2011.

Preece, R.C., Gowlett, J.A.J., Parfitt, S.A., Bridgland, D.R., and Lewis, S.G.: Humans in the Hoxnian habitat, context, and fire use at Beeches Pit, West Stow, Suffolk, UK, J. Quat. Sci 21:485-496, 2006.

10 Pretis, F., and Kaufmann, R.K.: Managing the Next Glacial Cycles via Carbon Concentrations. Working Paper, 2019. Pretis, F., Mann, M.L., and Kaufmann, R.K.: Testing competing models of the temperature hiatus: assessing the effects of conditioning variables and temperature uncertainties through sample-wide break detection, Climatic Change, 131(4): 705-718, 2015.

Pretis, F., Reade, J., \& Sucarrat, G.: Automated General-to-Specific (GETS) regression modeling and indicator saturation methods for the detection of outliers and structural breaks. Journal of Statistical Software, 86(3), 2018.

Riveiros N.V., Waelbroeck, C., Skinner, L., Duplessy, J.C., McManus, J.F., Kandiano, E., Bauch, H.A.: The "MIS 11 paradox" and ocean circulation: the role of millennial scale events, Earth and Planetary Science Letters, 371-372:258269, 2013.

Rohling, E.J., Braun, K., Grant, K., Kucera, M., Roberts, A.P., Siddall, M., and Trommer, G.: Comparison between

Holocene and Marine Isotope Stage-11 sea-level histories, Earth Planet. Sci. Lett., 291(1-4), 97-105,

doi:10.1016/j.epsl.2009.12.054, 2010

Ruddiman, W.F.: Orbital insolation, ice volume, and greenhouse gases, Quaternary Science Reviews, 22:1597-1629, 2003.

Ruddiman, W.F.: Ice-Driven CO2 feedback on ice volume, Climate of the Past, 2: 43-55, 2006.

25 Ruddiman, W.F.: The early anthropogenic hypothesis: challenges and responses, Rev. Geophys. 45:1-37, 2007.

Ruddiman, W.F. and Raymo, M.E.: A methane-based time scale for Vostok ice, Quaternary Science Reviews 22(24): 141-155, 2003.

Sarmiento, J., and Togeweiler, J.R.: A new model for the role of the oceans in determining pCO2, Nature 308:621624, 1984.

30 Schmittner A, Yashimore, M., and Weaver, A.J.: Instability of glacial climate in a model of the Ocean-AtmosphereCryosphere system, Science 295:1489-1493, 2002.

Schneider, L., Smerdon, J.E., Pretis, F., Hartl-Meier, C., \& Esper, J.: A new archive of large volcanic events over the past millennium derived from reconstructed summer temperatures. Environmental Research Letters, 12(9), 094005, 2017.

35 Seigenthaler, U., and Wenk, T.: Rapid atmospheric $\mathrm{CO}_{2}$ variations and ocean circulation, Nature 308:624-626, 1984. Shackleton, N.J: The 100,000 year ice-age cycle identified and found to lag temperature, carbon dioxide, and orbital eccentricity, Science 289:1897-1902, 2000.

Siddall, M. Rohling, E.J. Almogi-Labin, A. Hemleben, Ch. Meischner, D. Schmiezer, I. Smeed, D.A. 2003, Sea-Level fluctuations during the last glacial cycle, Letters to Nature, 423: 853-858. 
Skinner, L.C., Scrivner, A.E., Vance, D., Barker, S., Fallon, S., and Waelbroeck, C.: North Atlantic versus Southern Ocean contributions to a deglacial surge in deep ocean ventilation, Geology, 41(6):667-670, 2013.

Stephens, B.B., and Keeling, R.F.: The influence of Antarctic sea ice on glacial-interglacial CO2 variations, Nature 404:171-174, 2000.

5 Stern, D.I., and Kaufmann, R.K.: Anthropogenic and natural cause of climate change, Climatic Change, 122(1-2):257$269,2014$.

Stocker, T.F. and Johnson, S.J.: A minimum thermodynamic model for the bipolar seesaw, Paleoceanography, 18, 1087, 2003.

Toggweiler J.R., Russell, L., and Carson, S.R.: Midlatitude westerlies, atmospheric $\mathrm{CO}_{2}$ and climate change during

10 the ice ages, Paleoceanography, 21(2) PA2005, doi:10.1029/2005PA001154, 2006.

Tzedakis, P.C., Crucifix, M., Mitsui, T., and Wolff, E.M.: A simple rule to determine which insolation cycles lead to interglacials, Nature 542:427-432, 2017.

Tzedakis, P.C., Raynaud, D., McManus, J.F., Berger, A., Brovkin, V., and Kiefer, T.: Interglacial diversity, Nature Geoscience, 12:751-755, 2009.

15 Tzedakis, P. C.: The MIS 11 - MIS 1 analogy, southern European vegetation, atmospheric methane and the "early anthropogenic hypothesis", Clim. Past, 6, 131-144, https://doi.org/10.5194/cp-6-131-2010, 2010.

Tziperman, E., Raymo, M.E., Huybers, P., and Wunsch, C.: Consequences of pacing the Pleistocene 100 Kyr ice ages by nonlinear phase locking to Milankovitch forcing, Paleoceanography, 21:PA4206 doi:10.1029/2005PA001241, 2006.

20 Vidal, L., Labeyrie, L., Cortijo, E., Arnold, M., Duplessy, J.C., Michel, E., Becque, S., and vanWeering, T.C.E.: Evidence for changes in North Atlantic Deep Water linked to meltwater surges during the Heinrich events, Earth Planet Sci. Lett. 146:13-27, 1997.

Watson, A.J. and Naviera Garabato, A.C.: The role of Southern ocean mixing and upwelling in glacial-interglacial atmospheric CO2 change, Tellus 58B:73-87, 2006.

25 Wolff, E.W. Rankin, A.M., and Rothlisberger, R.: An ice core indicator of Antactic sea ice production? Geophys. Res. Lett. 30 doi:10.1029/2003GLO18454, 2003.

Wunsch, C.: Quantitative estimate of the Milankovitch-forced contribution to observed Quarternary climate change, Quaternary Science Reviews 23:1001-1012, 2004.

Yang, X., Pyle, J.A., and Cox, R.A.: Sea salt aerosol production and bromine release: Role of snow on sea ice Geophysical Research Letters 35(16): L16815, 2008.

Yin, Q.: Insolation-induced mid-Brunhes transition in Southern Ocean ventilation and deep-ocean temperature, Nature 494:222-225, 2013.

Yin, Q.Z., and Berger, A.: Individual contribution of insolation and $\mathrm{CO}_{2}$ to the interglacial climates of the past 800,000 years, Climate Dynamics 38:709-724, 2012.

35 Yule, G.: An Introduction to the Theory of Statistics, C. Griffin and Co., London, 1929. 


\section{Figure captions}

Fig. 1. The observed values for temperature (black line) and values simulated by the system model conditioned only on the four variables for solar insolation (red line). Thick portions of the red line represent time steps in which the simulation error is significantly different from zero (non-zero error). Red circles represent time steps when the simulation error is an (innovational) outlier. The light gray area is the out-of-sample forecast period; MIS 11 is shaded dark gray. (b) same as above for carbon dioxide, (c) same as above for methane, (d) same as above for land ice, (e) same as above for $\mathrm{Na}$, (f) same as above for $\mathrm{SO}_{4}$, (g) same as above for sea level, (h) same as above for $S S T^{l}$.

10 Fig. 2. The root mean square simulation errors for all ten endogenous climate variables simulated by the CVAR system model conditioned only on the four variables for solar insolation. RMSE for the in-sample period are shown as dark grey (left), out-of sample as grey (middle), and out-of sample excluding Marine Isotope Stage 11 as light grey (right).

Fig. 3. The number of outliers (red spikes) and non-zero errors (darkly shaded) for each time step. Marine isotope stages are indicated by alternating areas of shading.

Fig. 4: The value of Ice conditioned on orbital geometry only (green line), $\mathrm{CO}_{2}$ (red line), non-sea-salt sodium (blue line), $C a$ (yellow line), and SST (orange line). Values from the proxy record are given by the black line.

\footnotetext{
${ }^{1}$ Note that the series of SST exhibits non-zero simulation errors nearly throughout the sample, suggesting a nonzero bias throughout the observational record - simulated model values persistently exceed observations.
} 

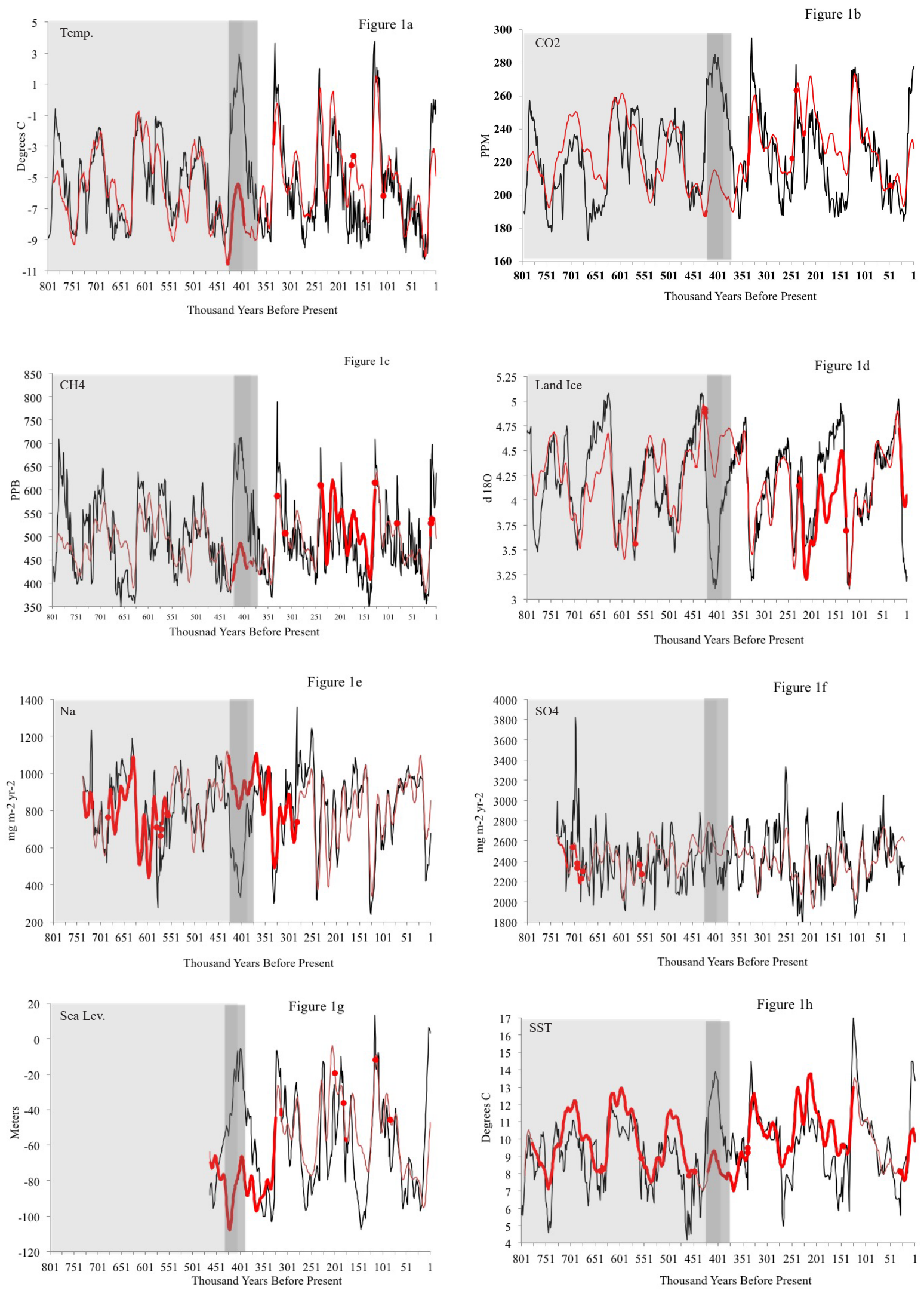
Figure 2
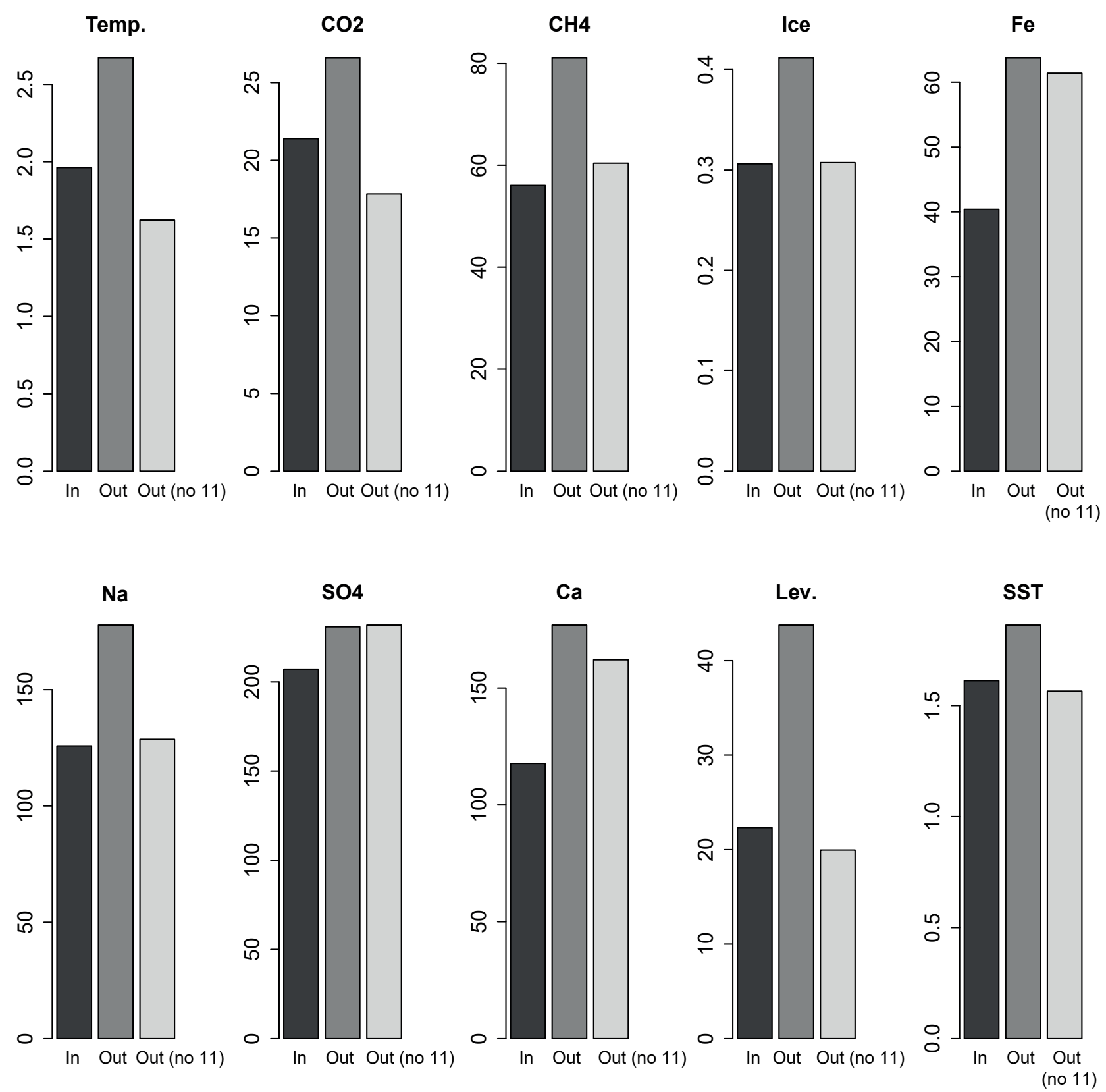
Figure 3

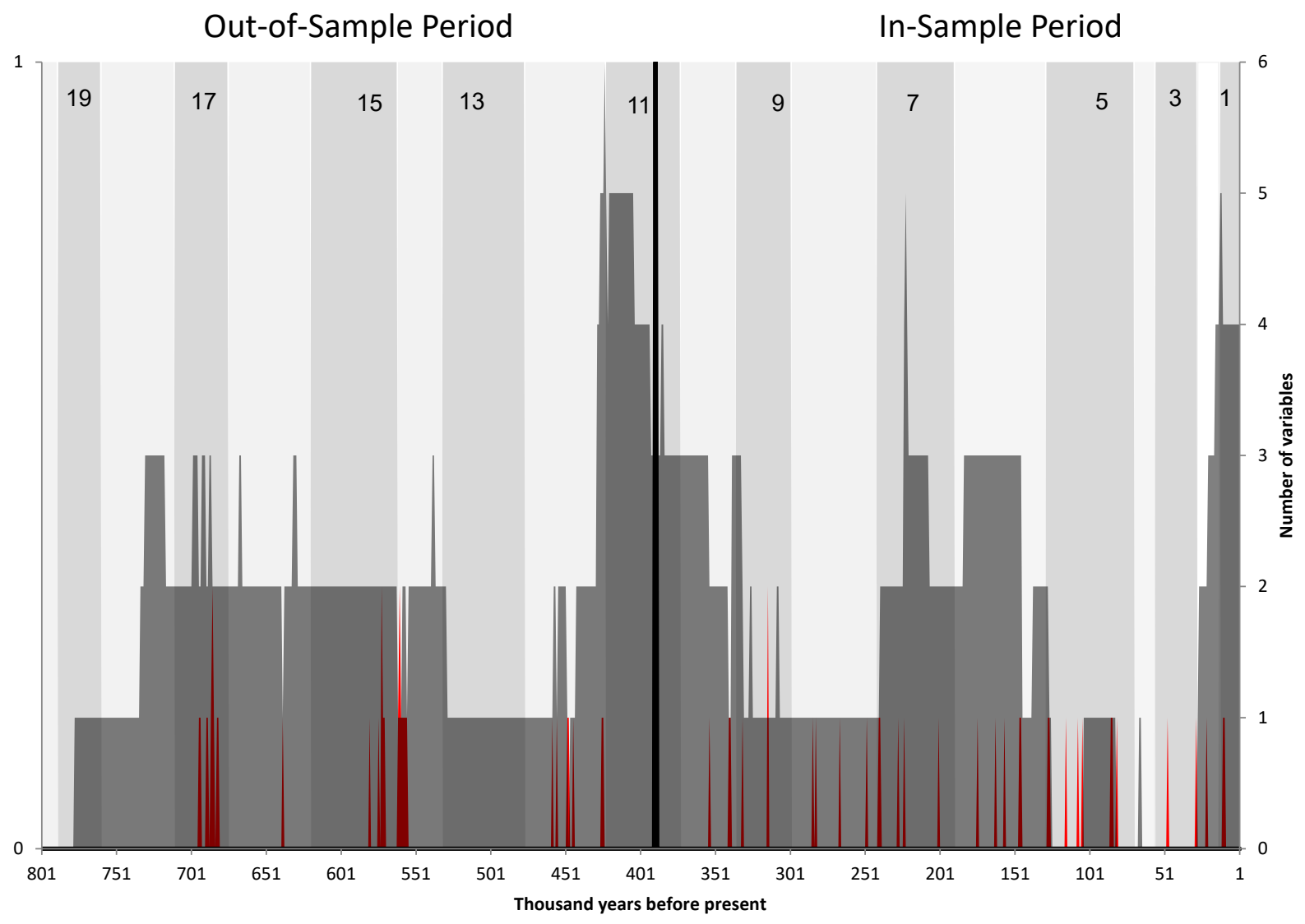


Figure 4

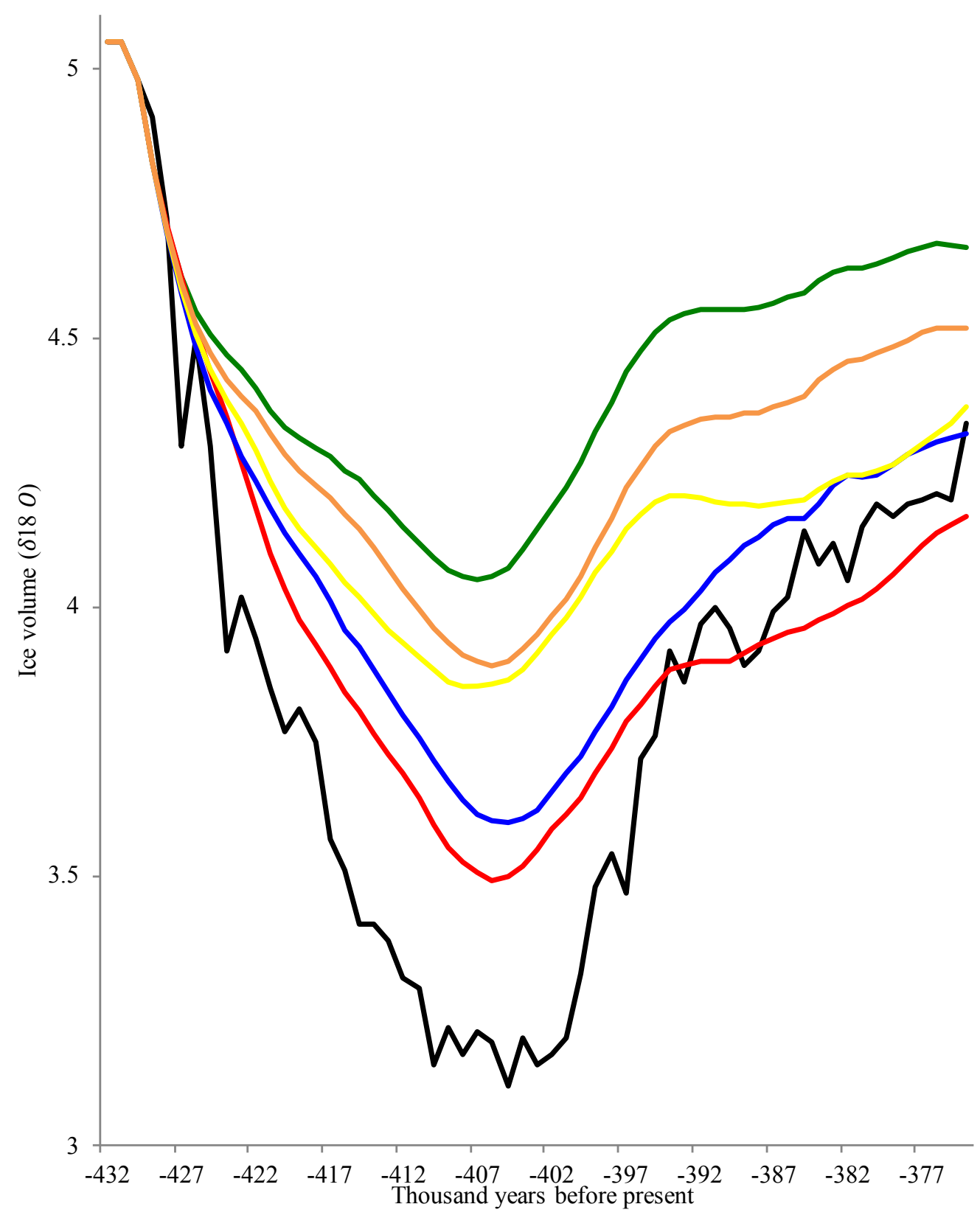


Table 1: Time series included in the CVAR

\begin{tabular}{|c|c|c|c|c|c|}
\hline Variable & Source & Unit & Time Scale & Obs & $\begin{array}{l}\text { First } \\
\text { Observation }\end{array}$ \\
\hline Temp & Jouzel et al., (2007) & $\begin{array}{l}\Delta \text { avg. last } 1 \\
\text { kyr }\end{array}$ & EDC3 & 710 & 801 kyr BP \\
\hline $\mathrm{CO}_{2}$ & Lüthi et al., 2008 & ppmv & ECD3 & 517 & 798 kyr BP \\
\hline $\mathrm{CH}_{4}$ & $\begin{array}{l}\text { Loulergue et al., } \\
\text { (2008) }\end{array}$ & ppbv & EDC3 & 1477 & 799 kyr BP \\
\hline Ice & $\begin{array}{l}\text { Lisiecki and Raymo, } \\
\text { (2005) }\end{array}$ & $\delta 180$ & LR04 & 390 & $801 \mathrm{kyr}$ BP \\
\hline $\mathrm{Fe}$ & Wolff et al. (2006) & $\mu g \mathrm{~m}^{-2} \mathrm{yr}^{-1}$ & EDC2 & 187 & $736 \mathrm{kyr} \mathrm{BP}$ \\
\hline $\mathrm{Na}$ & Wolff et al. (2006) & $\mu g \mathrm{~m}^{-2} \mathrm{yr}^{-1}$ & EDC2 & 195 & 739 kyr BP \\
\hline $\mathrm{SO} 4$ & Wolff et al. (2006) & 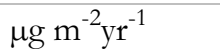 & EDC2 & 195 & 739 kyr BP \\
\hline $\mathrm{Ca}$ & Wolff et al. (2006) & $\mu \mathrm{g} \mathrm{m}^{-2} \mathrm{yr}^{-1}$ & EDC2 & 195 & 739 kyr BP \\
\hline Sea Level & Siddal et al., (2003) & Meters & SPECMAP & 125 & 466 kyr BP \\
\hline $\begin{array}{l}\text { Sea Surface } \\
\text { Temp }\end{array}$ & $\begin{array}{l}\text { Martinez-Garcia et al., } \\
\text { (2009) }\end{array}$ & Degrees C & EDC3 & 121 & $801 \mathrm{kyr}$ BP \\
\hline Eccentricity & Paillard et al., (1996) & $\begin{array}{l}\text { Dimensionless } \\
\text { index }\end{array}$ & - & 801 & $801 \mathrm{kyr}$ BP \\
\hline Obliquity & Paillard et al., (1996) & Degrees & - & 801 & $801 \mathrm{kyr}$ BP \\
\hline Precession & Paillard et al., (1996) & $\begin{array}{l}\text { Dimensionless } \\
\text { index }\end{array}$ & - & 801 & $801 \mathrm{kyr}$ BP \\
\hline $\begin{array}{l}\text { Seasonal } \\
\text { Insolation }\end{array}$ & Paillard et al., (1996) & $\mathrm{W} / \mathrm{m}^{2}$ & - & 801 & $801 \mathrm{kyr}$ BP \\
\hline
\end{tabular}


Table 2: Tests of simulation accuracy during various periods.

\begin{tabular}{|c|c|c|c|c|c|c|}
\hline \multirow[b]{3}{*}{ Variable } & \multicolumn{2}{|c|}{ In vs. out-of-sample } & \multicolumn{4}{|c|}{ Distribution among marine isotope stages } \\
\hline & \multirow[b]{2}{*}{ Outliers } & \multirow[b]{2}{*}{ Persisting errors } & \multicolumn{2}{|c|}{ Outliers } & \multicolumn{2}{|c|}{ Persisting errors } \\
\hline & & & All stages & $\begin{array}{l}\text { Stage } 11 \\
\text { excluded }\end{array}$ & $\begin{array}{ll}\text { All } & \text { S } \\
\text { stages } & \text { e }\end{array}$ & \\
\hline Temp & $3.0^{+}[0 / 3]$ & $19.8^{* *}[34 / 6]$ & 18.4 & 15.6 & $286.5^{* *}$ & $53.8^{* *}$ \\
\hline $\mathrm{CO}_{2}$ & $3.0^{++}[0 / 3]$ & $2.5[4 / 10]$ & 15.8 & 13.2 & $57.9^{* *}$ & $53.3^{* *}$ \\
\hline $\mathrm{CH}_{4}$ & $7.0^{* *+}[0 / 7]$ & $49.3^{* *}[31 / 117]$ & $46.5^{* *}$ & $39.7^{* *}$ & $535.9^{* *}$ & $571.8^{* *}$ \\
\hline Ice & $0.2[3 / 2]$ & $103.7^{* *}[4 / 116]$ & 14.9 & 3.8 & $543.0^{* *}$ & $506.5^{* *}$ \\
\hline $\mathrm{Fe}$ & $1.4[1 / 4]$ & $91.8^{* *}[226 / 79]$ & 19.1 & 12.6 & $325.4^{* *}$ & $313.5^{* *}$ \\
\hline $\mathrm{Na}$ & $4.2^{*+}[6 / 1]$ & $24.2^{* *}[172 / 107]$ & 28.2 & 3.5 & $356.0^{* *}$ & $342.2^{* *}$ \\
\hline SO4 & $7.9^{* *+}[7 / 0]$ & $40.7^{* *}[36 / 0]$ & $80.2^{* *}$ & 3.8 & $398.2^{* *}$ & $368.7^{* *}$ \\
\hline $\mathrm{Ca}$ & $1.3[3 / 1]$ & $24.3^{* *}[35 / 6]$ & 22.9 & 3.00 & $332.3^{* *}$ & $307.0^{* *}$ \\
\hline Sea Level & $0.8[0 / 4]$ & $136.3^{* *}[73 / 69]$ & 8.0 & 6.3 & $288.1^{* *}$ & $275.4^{* *}$ \\
\hline SST & $0.1[4 / 5]$ & $9.1^{* *}[357 / 282]$ & 20.0 & 11.6 & $101.7^{* *}$ & $101.6^{* *}$ \\
\hline All & $0.1[24 / 30]$ & $52.5^{* *}[972 / 793]$ & $37.9^{* *}$ & 3.5 & $561.4^{* *}$ & $427.7^{* *}$ \\
\hline
\end{tabular}

Value rejects the null hypothesis at $\mathrm{p}<.05\left(^{*}\right), \mathrm{p}<0.01$ respectively $\left(^{* *}\right)$. Blue indicates the out-of-sample simulation is more accurate than the in-sample simulation; red indicate the in-sample simulation is more accurate. Values in brackets indicate the number of outlier/persisting errors in the out-of-sample period relative to the number of outlier/nonzero mean errors in the in-sample period.. A large value implies that the in-sample simulation has significantly fewer outlier/persisting errors, which would make it more accurate than the out-of-sample simulation. 
Table 3: p-values for test of significance on $\theta_{j}$ (equation 8) for the sample that includes all endogenous variables. Red indicates rejection of the exclusion $(p<0.05)$ of lagged errors of other series, blue indicates rejection of the exclusion $(\mathrm{p}<0.10)$ of lagged errors of other series, and green indicates rejection of the exclusion for the autoregressive lags $(\mathrm{p}<0.05)$. The red value of 0.023 in the second column of the first row indicates that the indicates that the simulation errors for $\mathrm{CO} 2$ have information about the simulation errors for temperature.

\begin{tabular}{|c|c|c|c|c|c|c|c|c|c|c|}
\hline \multirow{2}{*}{$\begin{array}{l}\text { Dep. } \\
\text { Variable } \\
\text { Eq. } 8\end{array}$} & \multicolumn{10}{|c|}{ Non zero simulation error excluded from equation 8} \\
\hline & Temp & $\mathrm{CO}_{2}$ & $\mathrm{CH}_{4}$ & Ice & $\mathrm{Fe}$ & $\mathrm{Na}$ & $\mathrm{SO} 4$ & $\mathrm{Ca}$ & Level & SST \\
\hline Temp & 0.005 & 0.023 & 0.041 & 0.144 & 0.140 & 0.314 & 0.314 & 0.878 & 0.795 & 0.169 \\
\hline $\mathrm{CO}_{2}$ & 0.397 & 0.629 & 0.057 & 0.143 & 0.721 & 0.760 & 0.760 & 0.676 & 0.51 & 0.992 \\
\hline $\mathrm{CH}_{4}$ & 0.829 & 0.516 & 0.000 & 0.074 & 0.285 & 0.101 & 0.101 & 0.168 & 0.746 & 0.867 \\
\hline Ice & 0.421 & 0.148 & 0.496 & 0.277 & 0.270 & 0.334 & 0.334 & 0.393 & 0.272 & 0.051 \\
\hline $\mathrm{Fe}$ & 0.054 & 0.055 & 0.658 & 0.586 & 0.014 & 0.910 & 0.910 & 0.000 & 0.337 & 0.600 \\
\hline $\mathrm{Na}$ & 0.013 & 0.442 & 0.064 & 0.917 & 0.007 & 0.875 & 0.875 & 0.752 & 0.476 & 0.622 \\
\hline $\mathrm{SO} 4$ & 0.234 & 0.283 & 0.111 & 0.705 & 0.301 & 0.902 & 0.902 & 0.042 & 0.957 & 0.158 \\
\hline $\mathrm{Ca}$ & 0.044 & 0.842 & 0.884 & 0.902 & 0.032 & 0.475 & 0.475 & 0.006 & 0.965 & 0.106 \\
\hline Level & 0.259 & 0.152 & 0.422 & 0.028 & 0.405 & 0.415 & 0.415 & 0.938 & 0.637 & 0.617 \\
\hline$S S T$ & 0.015 & 0.036 & 0.368 & 0.052 & 0.949 & 0.119 & 0.119 & 0.271 & 0.969 & 0.000 \\
\hline
\end{tabular}


Table 4: p-values for test of significance on $\theta_{j}$ (equation 8) for the sample that includes variables other than sea-level. Red indicates rejection of the exclusion $(p<0.05)$ of lagged errors of other series, blue indicates rejection of the exclusion $(p<0.10)$ of lagged errors of other series, green indicates rejection of the exclusion for the autoregressive lags.

\begin{tabular}{l|cccccccccc}
$\begin{array}{l}\text { Dependent } \\
\text { variable }\end{array}$ & \multicolumn{8}{c}{ Non zero simulation error excluded from equation 8} \\
Eq. 8 & $\mathrm{Temp}$ & $\mathrm{CO}_{2}$ & $\mathrm{CH}_{4}$ & $\mathrm{Ice}$ & $\mathrm{Fe}$ & $\mathrm{Na}$ & $\mathrm{SO}_{4}$ & $\mathrm{Ca}$ & $\mathrm{SST}$ \\
\hline $\mathrm{Temp}$ & 0.009 & 0.311 & 0.128 & 0.349 & 0.173 & 0.644 & 0.890 & 0.571 & 0.187 \\
$\mathrm{CO}_{2}$ & 0.186 & 0.852 & 0.213 & 0.136 & 0.700 & 0.312 & 0.866 & 0.149 & 0.847 \\
$\mathrm{CH}_{4}$ & 0.454 & 0.471 & 0.362 & 0.371 & 0.568 & 0.181 & 0.878 & 0.775 & 0.886 \\
$\mathrm{Ice}$ & 0.314 & 0.006 & 0.584 & 0.000 & 0.035 & 0.228 & 0.370 & 0.046 & 0.055 \\
$\mathrm{Fe}$ & 0.189 & 0.202 & 0.394 & 0.860 & 0.064 & 0.711 & 0.976 & 0.059 & 0.791 \\
$\mathrm{Na}$ & 0.212 & 0.668 & 0.632 & 0.881 & 0.272 & 0.812 & 0.066 & 0.687 & 0.932 \\
$\mathrm{SO}$ & 0.166 & 0.226 & 0.039 & 0.881 & 0.736 & 0.460 & 0.000 & 0.025 & 0.246 \\
$\mathrm{Ca}$ & 0.094 & 0.954 & 0.766 & 0.955 & 0.376 & 0.024 & 0.000 & 0.113 & 0.204 \\
$\mathrm{SST}$ & 0.714 & 0.011 & 0.326 & 0.012 & 0.973 & 0.337 & 0.715 & 0.180 & 0.133
\end{tabular}

